Check for updates

Cite this: RSC Adv., 2020, 10, 14689

March 2020

Accepted 3rd April 2020

DOI: $10.1039 / d 0 r a 02293 d$

rsc.li/rsc-advances

\section{The curious case of salicylidene-based fluoride sensors: chemosensors or chemodosimeters or none of them $\uparrow$}

\author{
Sandeep Kumar Dey ${ }^{\star a}$ and Christoph Janiak (D) *b
}

\begin{abstract}
Fluoride-ion induced hydrolysis of imine $(\mathrm{C}=\mathrm{N})$ bonds has not been documented in the literature, in spite of the numerous salicylidene-based fluoride sensors studied over the years. Herein, we have proposed a mechanism for fluoride-ion induced hydrolysis of salicylidene compounds ( $S L$ and $C L 1-3$ ) based on ${ }^{1} \mathrm{H}-\mathrm{NMR},{ }^{19} \mathrm{~F}-\mathrm{NMR}, \mathrm{LC}-\mathrm{MS}$ and UV-vis spectroscopy experiments.
\end{abstract}

\section{Introduction}

Chromogenic and fluorogenic anion sensing has witnessed extensive research interest over the past two decades due to instant detection of anions of biological and environmental relevance by visual colour change, or highly sensitive spectrophotometric techniques. ${ }^{1}$ Several salicylidene Schiff-base compounds have been synthesized for anion sensing over the years due to their facile synthetic procedures and their anionbinding constants have been determined. ${ }^{2}$ It is interesting to note that all salicylidene-based anion sensors have been reported to sense fluoride and often acetate in aprotic organic media, with visible colour changes. ${ }^{2,3}$ The mechanism of sensing has been attributed to either $-\mathrm{OH}^{\cdots} \mathrm{F}^{-}$hydrogen bonding or $-\mathrm{OH}$ deprotonation by fluoride to give $\mathrm{HF} / \mathrm{HF}_{2}{ }^{-}$in solution. ${ }^{3}$ However, it is surprising to note that no crystal structures of hydrogen-bonded salicylidene receptor-fluoride complexes or deprotonated salicylidene receptor (with fluoride-supplied counter-cations) has been reported in any of the published literature, to the best of our knowledge. In contrast, anion receptors with $-\mathrm{NH}$ hydrogen bond donor groups (such as amide, urea, pyrrole, indole and even amines) are often reported with crystal structures of receptor-anion complexes or deprotonated receptor alongside their solution state anion binding properties. ${ }^{4}$ Given the numerous reports on salicylidene based anion sensors, ${ }^{2,3}$ it is hard to assume that no one has ever tried crystallization of a salicylidene receptor with fluoride but might have failed in their attempts. We have been

${ }^{a}$ School of Chemical Sciences, Goa University, Taleigao Plateau, Goa 403206, India. E-mail: sandeepdey@unigoa.ac.in; Tel: +91-7387633550

${ }^{b}$ Institute for Inorganic and Structural Chemistry, Heinrich-Heine University Düsseldorf, 40225 Düsseldorf, Germany. E-mail: janiak@uni-duesseldorf.de; Tel: $+49-2118112286$

$\dagger$ Electronic supplementary information (ESI) available: Synthesis details with NMR and IR spectra of Schiff bases, ${ }^{1} \mathrm{H}$ and ${ }^{19} \mathrm{~F}$-NMR spectra of reaction with fluoride and UV-vis spectra of SL and CL1-3 in presence of TBAF. See DOI: $10.1039 /$ d0ra02293d curious to understand, why is it difficult to obtain crystals of salicylidene receptor-fluoride complex or deprotonated salicylidene receptor. In order to address this question, we have analyzed the mechanism of fluoride sensing/binding by a new salicylidene based tripodal amide receptor (SL) and three salicylidene control compounds (CL1-3) based on commercially available aromatic amines (Scheme 1).

It is important to mention that the objective here is not to explore the fluoride sensing properties of salicylidene Schiffbases but to address the limitations of their applicability as fluoride sensors which have not been addressed before. Our finding of a fluoride-induced imine-bond hydrolysis strongly suggests that regenerated salicylaldehyde can also behave as a fluoride-ion sensor even after the salicylidene Schiff-base has hydrolyzed in solution. This implies that the optical properties

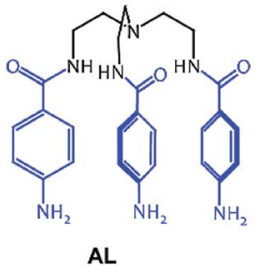

AL

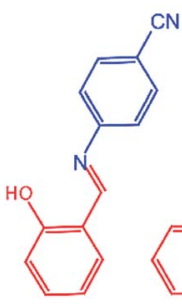

CL1

N
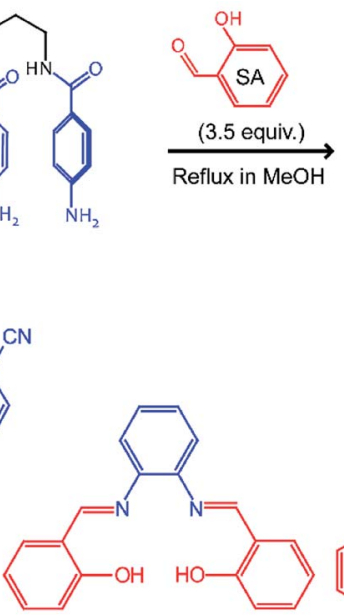

CL2

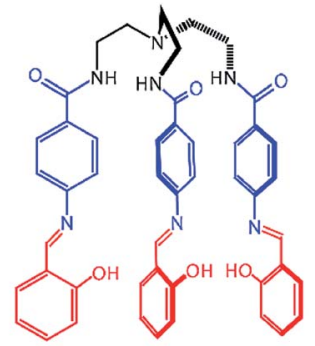

SL

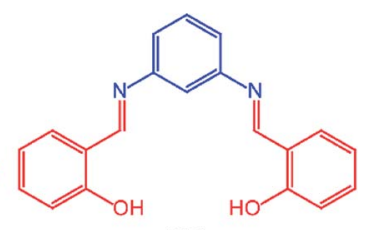

CL3
Scheme 1 Molecular structures of tripodal salicylidene receptor SL synthesized from tris(4-amino- $N$-ethylbenzamide)amine $A L$ and salicylaldehyde SA, and control receptors CL1-3 (synthesis details are provided in the ESI $\uparrow$ ). 
shown by the regenerated salicylaldehyde in presence of fluoride could be mistaken as fluoride sensing by salicylidene Schiff-bases.

\section{Results and discussions}

${ }^{1}$ H-NMR spectra of SL or CL1-3 recorded in the presence of fluoride salt(s) showed interesting results which was either not addressed or observed in earlier reports on salicylidene-based fluoride sensors. Our ${ }^{1} \mathrm{H}-\mathrm{NMR}$ experimental results showed initial deprotonation of salicylidene- $\mathrm{OH}$ in SL followed by slow hydrolysis of imine bonds in the presence of fluoride salts (as TBAF/CsF with TBA $=$ tetra- $n$-butylammonium). Similar to SL, ${ }^{1} \mathrm{H}-\mathrm{NMR}$ results showed hydrolysis of imine bond(s) in control compounds CL1-3 in the presence of a fluoride salt both in dimethyl sulfoxide- $\mathrm{d}_{6}\left(\right.$ DMSO- $\left.\mathrm{d}_{6}\right)$ and chloroform- $\mathrm{d}_{1}\left(\mathrm{CDCl}_{3}\right)$. This raises the fundamental question if salicylidene-based anion receptors are applicable as fluoride sensors to begin with.

The ${ }^{1} \mathrm{H}-\mathrm{NMR}$ spectrum of SL in DMSO- $d_{6}(0.6 \mathrm{~mL})$ showed the $-\mathrm{OH}$ signal at $12.8 \mathrm{ppm}$, imine $-\mathrm{N}=\mathrm{CH}$ at $8.9 \mathrm{ppm}$ and amide $-\mathrm{NH}$ at $8.4 \mathrm{ppm}$ (Fig. 1). Addition of TBAF (10 equiv.) showed a large upfield shift of the $-\mathrm{OH}$ signal $(\Delta \delta=2.1 \mathrm{ppm})$ with concomitant broadening indicative of $\mathrm{O}-\mathrm{H} \cdots \mathrm{F}^{-}$hydrogen bonds, and also showed the emergence of a new peak at $10.1 \mathrm{ppm}$ together with several low intensity peaks appearing in the aromatic region (D1, Fig. 1) within an hour. Appearance of

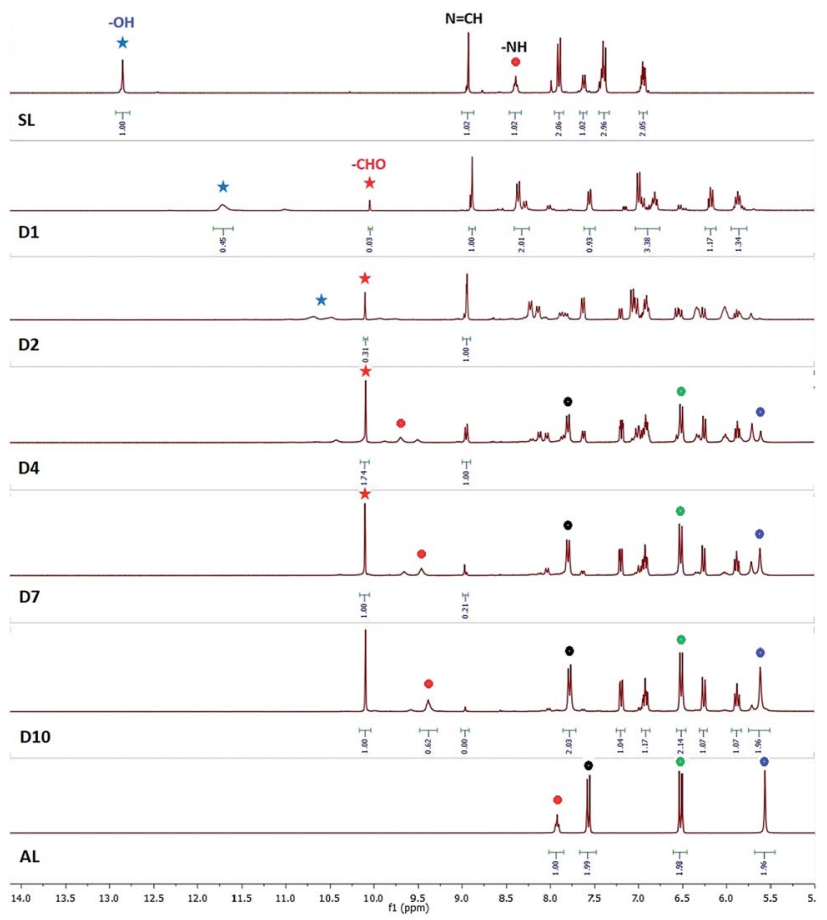

Fig. $1{ }^{1} \mathrm{H}$-NMR spectra (DMSO- $d_{6}$ ) of $\mathrm{SL}$ in the presence of TBAF for 10 days (D1-D10). Signals labelled with red, black, green and blue circles indicate amide $-\mathrm{NH}$, ortho- $\mathrm{CH}$, meta- $\mathrm{CH}$ and $-\mathrm{NH}_{2}$ protons of $\mathrm{AL}$ respectively. Signals labelled with red, and blue stars indicate $-\mathrm{CHO}$ and $-\mathrm{OH}$ protons of salicylaldehyde and SL respectively. (A larger sized version of the spectra with also additional spectra recorded on D3 and D9 is provided in Fig. S20, ESI $\dagger$ ). the new peak at $10.1 \mathrm{ppm}(-\mathrm{CHO})$ was a possible indication towards the formation of salicylaldehyde by imine bond cleavage in SL. ${ }^{1} \mathrm{H}-\mathrm{NMR}$ of the solution mixture (SL and TBAF) when recorded on the next day (after $24 \mathrm{~h}$ ) showed further upfield shift and broadening of the $-\mathrm{OH}$ signal (D2, Fig. 1), indicating gradual deprotonation of the $-\mathrm{OH}$ protons. Disappearance of the salicylidene -OH proton upon addition of TBAF has also been observed for the reported salicylidene-based anion sensors. ${ }^{2,3}$ Further, the intensity of the salicylaldehyde -CHO peak at $10.1 \mathrm{ppm}$ strengthens along with the other new aromatic peaks notably the $-\mathrm{NH}_{2}$ peak of regenerated $\mathbf{A L}$ at $5.6 \mathrm{ppm}$, validating the slow hydrolysis of the SL imine bonds. It was expected that the hydrolysis of imine bonds would finally lead to the disappearance of the imine $-\mathrm{N}=\mathrm{CH}$ proton signal at $8.9 \mathrm{ppm}$ and thus, we continued to record the ${ }^{1} \mathrm{H}-\mathrm{NMR}$ spectra of the solution mixture till complete hydrolysis resulted. Complete hydrolysis of SL was observed after 9 days (D10, Fig. 1), where the $-\mathrm{N}=\mathrm{CH}$ proton signal has disappeared almost completely and the aromatic proton signals corresponding to regenerated AL and deprotonated salicylaldehyde could be observed distinctly. Integration of the $-\mathrm{CHO}$ and $-\mathrm{N}=\mathrm{CH}$ peaks of the spectra showed $23 \%, 44 \%, 64 \%, 83 \%$ and $93 \%$ hydrolysis on day2, day3, day4, day7 and day9 respectively (Fig. S20, ESI $\dagger$ ). It is noted that upon complete hydrolysis, the amide $-\mathrm{NH}$ and an aromatic - $\mathrm{CH}$ proton (ortho to the amide group) signals in regenerated AL was downfield shifted with respect to the ${ }^{1} \mathrm{H}$ NMR spectrum of $\mathbf{A L}$ due to hydrogen bonding interactions with fluoride present in the solution mixture (D10 and AL, Fig. 1). Downfield shift of amide $-\mathrm{NH}$ and ortho- $\mathrm{CH}$ protons in the presence of TBAF has previously been observed for Trenbased tripodal amide receptors. ${ }^{5}{ }^{19} \mathrm{~F}-\mathrm{NMR}$ of the solution showed two peaks occurring at -69 and $-138 \mathrm{ppm}$ for fluoride and hydrogen difluoride $\left(\mathrm{HF}_{2}{ }^{-}\right)$anions respectively (Fig. S25, ESI $\dagger$ ). The in situ formation of the $\mathrm{HF}_{2}{ }^{-}$anion is discussed later in the plausible mechanism of imine-bond hydrolysis by fluoride (Scheme 2). The liquid chromatography-mass spectrum (LC-MS) of the NMR solution mixture (diluted with acetonitrile) recorded after 10 days showed $m / z$ at $504.27\left(\mathbf{A L}+\mathbf{H}^{+}\right)$, and no peak at $m / z 816.34\left(\mathbf{S L}+\mathbf{H}^{+}\right)$was observed, thereby supporting

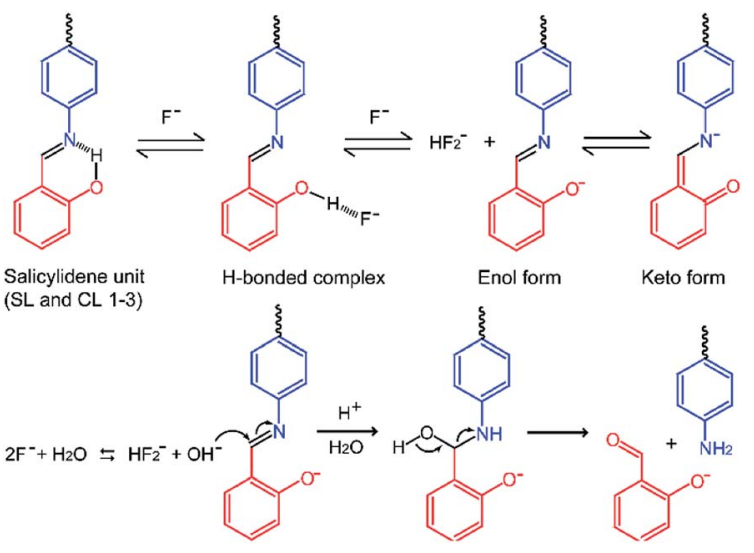

Scheme 2 Plausible mechanism for the fluoride ion induced imine bond hydrolysis in salicylidene based Schiff bases SL and CL1-3. 
the suggested complete hydrolysis of $\mathbf{S L}$ to $\mathbf{A L}$ and salicylaldehyde (Fig. S21 and S22, ESI $\dagger$ ).

In another experiment, addition of CsF (10 equiv.) to a DMSO- $d_{6}$ solution $(0.6 \mathrm{~mL})$ of SL showed immediate disappearance of the $-\mathrm{OH}$ signal, the downfield shift of the amide -NH signal $(\Delta \delta=0.9 \mathrm{ppm})$ with concomitant broadening, and the distinct resolution of six different types of aromatic protons with upfield or downfield shifts (Fig. S23, ESI $\dagger$ ). ${ }^{1} \mathrm{H}-\mathrm{NMR}$ of the solution mixture ( $\mathbf{S L}$ and $\mathrm{CsF}$ ) recorded on the next day (after 24 h) showed a feeble appearance of the - $\mathrm{CHO}$ peak at $10.1 \mathrm{ppm}$ which subsequently intensified in the spectra recorded on successive days. In contrast to the complete hydrolysis of SL observed with TBAF, only $50 \%$ hydrolysis of SL was observed to be completed with CsF in 10 days, possibly due to the weaker dissociation of CsF in an aprotic medium compared to TBAF (further hydrolysis could be observed on successive days). No observable shift of the imine $-\mathrm{N}=\mathrm{CH}$ signal was noticed, however the signal gradually split into two peaks (separated by $0.03 \mathrm{~Hz}$ ) possibly due to the presence of both keto and enol forms of deprotonated SL in the presence of fluoride salt, which has also been observed in the spectra showing hydrolysis of SL by TBAF. Imine bond cleavage of SL has also been observed in the presence of KF (Fig. S24, ESI †े).

To understand the origin of hydrolysis of SL in the presence of TBAF/CsF, we have recorded ${ }^{1} \mathrm{H}-\mathrm{NMR}$ spectra of SL in the presence of $\mathrm{Cs}_{2} \mathrm{CO}_{3}$. Carbonate being a stronger base than fluoride would result in a faster base-catalyzed hydrolysis of SL. However, the spectral changes were largely the same as observed with CsF. A DMSO- $\mathrm{d}_{6}$ solution $(0.6 \mathrm{~mL})$ of SL and $\mathrm{Cs}_{2} \mathrm{CO}_{3}$ (3 equiv.) showed the appearance of the salicylaldehyde -CHO signal at $10.1 \mathrm{ppm}$ with $37 \%$ hydrolysis completed in 24 hours. The solution mixture when recorded on the subsequent days showed up to $70 \%$ hydrolysis beyond which no further hydrolysis was observed (Fig. S26, ESI†). Due to solubility issue, addition of more than 3 equiv. of $\mathrm{Cs}_{2} \mathrm{CO}_{3}$ into the NMR solution was not achieved.

In order to further validate the fluoride-ion induced hydrolysis of imine bonds, we have synthesized three salicylidenebased control compounds CL1-3 (Scheme 1). Structurally similar Schiff bases have previously been reported as fluoride sensors in aprotic media. ${ }^{2,3}{ }^{1} \mathrm{H}$-NMR experiments revealed that, addition of 2 equiv. of TBAF to a solution of CL1 in DMSO- $\mathrm{d}_{6}$ showed $50 \%$ hydrolysis in one hour and complete hydrolysis within 24 hours (Fig. 2), also confirmed by LC-MS (Fig. S29, ESI $\dagger$ ). However, hydrolysis was observed to be much faster in $\mathbf{C D C l}_{3}$, with $90 \%$ hydrolysis of CL1 in one hour in the presence of 2 equiv. of TBAF (Fig. S28, ESI $†$ ). Thus, it is understood that the nature of solvents significantly affects the rate of imine bond hydrolysis, where the solubility of the salicylidene compound, solvent polarity and extent of dissociation of the fluoride salt into free ions might play a crucial role.

Both CL2 and CL3 (positional isomers) have two imine linkages, and addition of excess TBAF (5 equiv.) resulted in the hydrolysis of only one imine bond which was confirmed by LCMS and ${ }^{1} \mathrm{H}$-NMR experiments. Addition of 2 equiv. of TBAF to a solution of CL2 in DMSO- $\mathrm{d}_{6}$ showed about $40 \%$ hydrolysis after 24 hours (D2 in Fig. S30, ESI $\dagger$ ), beyond which no further

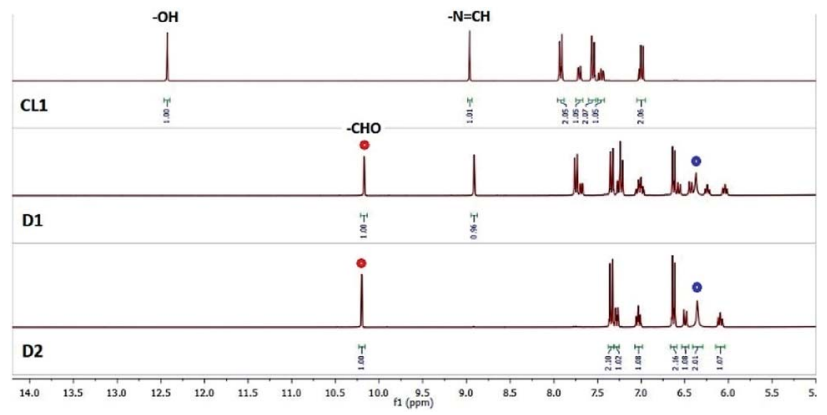

Fig. $2{ }^{1} \mathrm{H}-\mathrm{NMR}$ spectra (DMSO- $d_{6}$ ) of CL1 in the presence of TBAF for 2 consecutive days (D1-D2). Signals labelled with red and blue circles indicate $-\mathrm{CHO}$ and $-\mathrm{NH}_{2}$ protons of regenerated salicylaldehyde and 4-aminobenzonitrile, respectively.

hydrolysis was observed (D3 in Fig. S30, ESI†). Addition of 3 more equivalents of TBAF to the solution mixture showed further hydrolysis of imine bonds revealing $50 \%$ hydrolysis of CL2 beyond which again no further hydrolysis was observed (D4 and D5, Fig. S30, ESI†). The LC-MS of the NMR solution mixture (diluted with acetonitrile) recorded after 6 days showed $\mathrm{m} / \mathrm{z}$ at 213.10, which suggests partial hydrolysis of CL2 with the loss of only one salicylaldehyde molecule (Fig. S32, ESI $\dagger$ ). ${ }^{19}$ F-NMR of the solution showed two peaks at -69 and -138 ppm for fluoride and hydrogen difluoride $\left(\mathrm{HF}_{2}{ }^{-}\right)$anions, respectively (Fig. S33, ESI $\dagger$ ), similar to that observed for SL added with TBAF. Hydrolysis of CL2 in the presence of TBAF has also been observed in $\mathrm{CDCl}_{3}$ (Fig. S31, ESI $\dagger$ ).

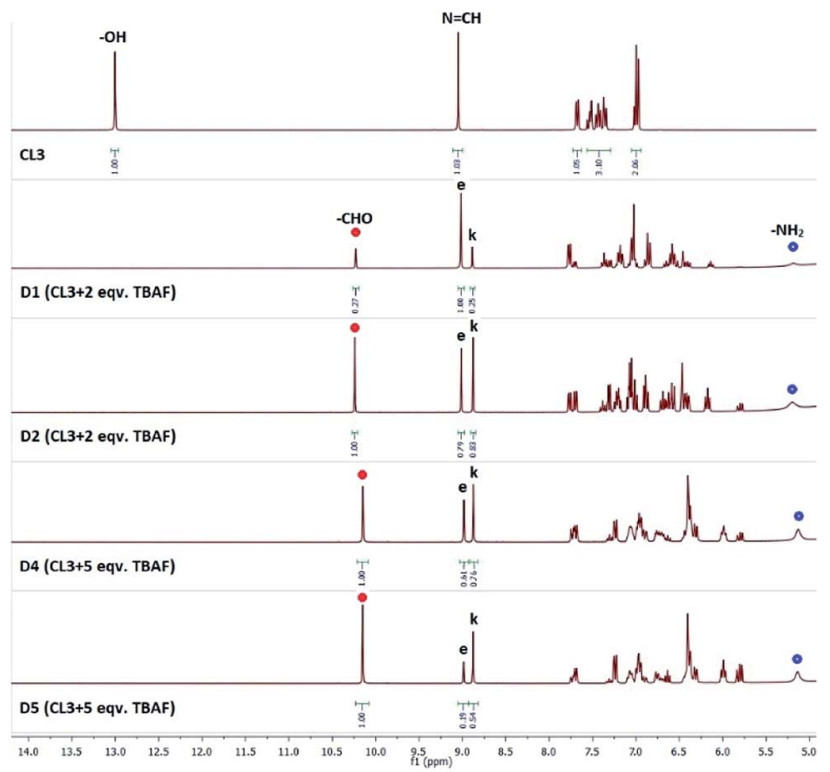

Fig. $3{ }^{1} \mathrm{H}$-NMR spectra (DMSO- $d_{6}$ ) of CL3 in the presence of TBAF for 5 consecutive days (D1-D5). Signals labelled with (e) and (k) indicate the enol and keto forms of $\mathrm{CL3}$, respectively. Signals labelled with red and blue circles indicate $-\mathrm{CHO}$ and $-\mathrm{NH}_{2}$ protons of salicylaldehyde and regenerated amine, respectively. (Additional spectra recorded for D3, D7 and D10 are provided in Fig. S34, ESI†). 
(a)

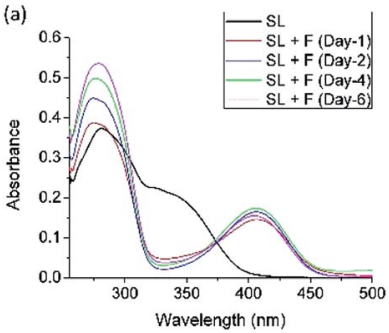

(b)

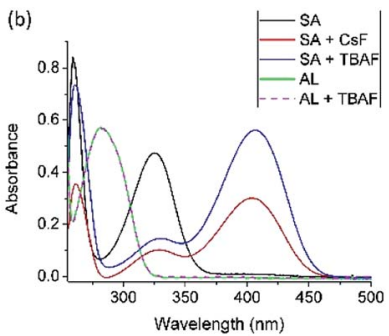

Fig. 4 (a) UV-vis spectra of SL $\left(1 \times 10^{-5} \mathrm{~mol} \mathrm{~L}^{-1}\right)$ in presence of TBAF (10 equiv.) recorded over a period of one-week (b) UV-vis spectra of AL $\left(1 \times 10^{-5} \mathrm{~mol} \mathrm{~L}^{-1}\right)$ and salicylaldehyde (SA) in presence of TBAF and/or CsF (day-1: spectrum was recorded immediately after addition of TBAF to a SL solution, day-2: the solution mixture of SL and TBAF of day-1 was recorded after 24 hours, and so on).

Similar experiments have been carried out with CL3 which showed about $38 \%$ hydrolysis in the presence of 2 equivalents of

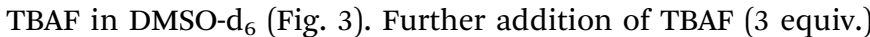
revealed $55 \%$ hydrolysis in 5 days beyond which no further hydrolysis observed (Fig. 3 and S34, ESI $\dagger$ ). LC-MS of the NMR solution mixture (diluted with acetonitrile) showed $\mathrm{m} / \mathrm{z}$ at 213.10 (Fig. S35, ESI $\dagger$ ), similar to CL2. Interestingly, upon addition of TBAF to $\mathbf{C L 3}$ solution, the singlet peak of $-\mathrm{N}=\mathrm{CH}$ (9.0 ppm) splits into two distinct peaks occurring at 8.9 and 9.0 ppm further confirming the presence of both keto and enol forms of salicylidene compounds in presence of fluoride (Fig. 3), as discussed earlier for SL. Splitting of the $-\mathrm{N}=\mathrm{CH}$ peak has also been observed for CL2 in presence of TBAF with a separation of $0.01 \mathrm{~Hz}$, similar to those observed for SL (Fig. 1).

Thus, due to the apparently unavoidable imine-bond hydrolysis it would not seem possible to obtain crystal structures of hydrogen-bonded salicylidene receptor-fluoride complex or deprotonated salicylidene receptor. We note that the presence of water is hard to avoid as the fluoride-containing medium is hygroscopic (TBAF and CsF salts are hygroscopic). Based on the ${ }^{1} \mathrm{H}-\mathrm{NMR}$ experimental results, we have deduced a mechanism for fluoride-ion induced imine-bond hydrolysis as depicted in Scheme 2. Before discussing the mechanism, it is important to learn that some urea-based anion receptors when crystallized in the presence of excess TBAF formed crystals of hydrogen bonded urea-bicarbonate (or urea-carbonate) complex. ${ }^{6}$ It has been proposed that two fluoride ions react with a water molecule to generate $\mathrm{OH}^{-}$and $\mathrm{HF}_{2}{ }^{-}$anions $\left(2 \mathrm{~F}^{-}+\right.$ $\mathrm{H}_{2} \mathrm{O} \leftrightarrows \mathrm{OH}^{-}+\mathrm{HF}_{2}{ }^{-}$). Hydroxide formed then reacts with $\mathrm{CO}_{2}$ at the air-solvent interface to form bicarbonate. Along this line, it can be argued that the fluoride induced in situ generation of hydroxide ions is quite feasible in the solutions containing salicylidene compounds mixed with fluoride salt.

The first two steps in the proposed mechanism (Scheme 2) are based on the mechanisms proposed for fluoride sensing by the reported salicylidene based sensors, ${ }^{3}$ and further supported by our experimental observations. In the first step, a fluoride ion forms a transient hydrogen-bonded complex with the $-\mathrm{OH}$ group of salicylidene unit followed by deprotonation of $-\mathrm{OH}$ (due to the basicity of fluoride and acidic nature of phenolic $-\mathrm{OH})$ releasing $\mathrm{HF}$ which combines with another $\mathrm{F}^{-}$ion $\left(\mathrm{F}^{-}\right.$

being present in excess) to give $\mathrm{HF}_{2}{ }^{-}$and the deprotonated receptor in the second step. The deprotonated enol form is in equilibrium with the keto form as observed in the ${ }^{1} \mathrm{H}-\mathrm{NMR}$ spectra of SL and CLs which are mixed with fluoride salt, showing the splitting of the imine $-\mathrm{N}=\mathrm{CH}$ proton signals. In the third step, a nucleophilic attack of the in situ generated hydroxide ion $\left(2 \mathrm{~F}^{-}+\mathrm{H}_{2} \mathrm{O} \leftrightarrows \mathrm{OH}^{-}+\mathrm{HF}_{2}{ }^{-}\right)$on the imine carbon followed by protonation of the imine nitrogen in the solution forms hydroxy(phenylamino)methyl phenolate. Finally, formation of the $\mathrm{C}=\mathrm{O}$ double bond by the loss of the $\mathrm{O}-\mathrm{H}$ proton results in the cleavage of $\mathrm{C}-\mathrm{N}$ bond to give salicylaldehyde and respective aromatic amine.

To further understand the fluoride-induced hydrolysis of salicylidene compounds, we have carried out UV-vis spectrophotometric studies of SL and CL1-3. The UV-vis spectrum of SL in DMSO $\left(1 \times 10^{-5} \mathrm{~mol} \mathrm{~L}^{-1}\right)$ showed two absorption bands at $280 \mathrm{~nm}$ and $345 \mathrm{~nm}$. Addition of fluoride salt (10 equiv.) resulted in the development of a new band at $410 \mathrm{~nm}$ responsible for the visible change in colour from colourless to yellow (Fig. 4a). No significant visible spectral changes of the solution mixture $\left(\mathbf{S L}+\mathbf{F}^{-}\right)$were observed over a period of one week (Fig. 4a), although we were expecting the absorbance at $410 \mathrm{~nm}$ to be significantly reduced due to hydrolysis of imine bonds (loss of conjugation). Similar spectral behaviours have also been observed for a DMSO solution mixture of CL added with TBAF (Fig. S38-S40, ESI $\dagger$ ). To understand this, we have carried out control experiments with DMSO solutions of salicylaldehyde and AL. No spectral changes have been observed upon addition of TBAF to a solution of $\mathbf{A L}\left(1 \times 10^{-5} \mathrm{~mol} \mathrm{~L}^{-1}\right)$ showing absorption at $280 \mathrm{~nm}$. However, UV-vis spectral analysis of salicylaldehyde $\left(1 \times 10^{-5} \mathrm{~mol} \mathrm{~L}^{-1}\right)$ in the presence of CsF or TBAF showed the emergence of a new peak at $405 \mathrm{~nm}$ (Fig. 4b), with concomitant change in colour from colourless to yellow (Fig. S41, ESI $\dagger$ ). Thus, it is confirmed that salicylaldehyde alone can behave as a colorimetric sensor for fluoride. This is the reason why imine-bond hydrolysis did not show any effect on the absorption of a fluoride-containing SL or CL solution.

Thus, deprotonated salicylaldehyde formed by fluoride-ion induced imine bond hydrolysis could be mistaken as fluoride sensing by salicylidene Schiff-bases.

\section{Conclusion}

In conclusion, we have demonstrated a fluoride-ion induced imine-bond hydrolysis in salicylidene-based receptors and proposed a mechanism based on ${ }^{1} \mathrm{H}-\mathrm{NMR},{ }^{19} \mathrm{~F}-\mathrm{NMR}$, LC-MS and UV-vis experiments. However, one question that needs to be addressed in this context is that "if the salicylidene Schiff-base sensor molecule which hydrolyses in the presence of a fluoride salt, can it be called a fluoride sensor"? The answer to this is arguable, because if the receptor and the analyte react to produce a new compound (in situ) resulting in changes in absorbance/ fluorescence/NMR peaks, it can be called a reactive sensor or chemodosimeter, ${ }^{7}$ but not when the original starting materials, here salicylaldehyde, are regenerated. Finally, the fact that salicylaldehyde can sense fluoride by distinctive colour changes (colourless to yellow) due to the emergence of a peak above 
$400 \mathrm{~nm}$ is concerned with the applicability of several salicylidene Schiff-base sensors showing similar fluoride induced colour changes due to absorption at 400-450 $\mathrm{nm}$ responsible for transmittance of yellow colour.

Thus, the overall results discussed here concerned the applicability of salicylidene Schiff bases as fluoride sensors in aprotic media which we suggest rather as a regenerated salicylaldehyde fluoride-ion sensing.

\section{Conflicts of interest}

There are no conflicts to declare.

\section{Acknowledgements}

SKD acknowledges the Department of Science and Technology (DST) India, for providing financial support through INSPIRE Faculty award (DST/INSPIRE/04/2016/001867). We thank the Alexander von Humboldt Foundation, Germany for providing the opportunity for research collaboration.

\section{References}

1 (a) M. E. Moragues, R. Martínez-Máñez and F. Sancenón, Chem. Soc. Rev., 2011, 40, 2593-2643; (b) C. Suksaia and T. Tuntulani, Chem. Soc. Rev., 2003, 32, 192-202; (c) R. Martínez-Máñez and F. Sancenón, Chem. Rev., 2003, 103, 4419-4476; (d) S. K. Dey, M. A. Kobaisi and S. V. Bhosale, ChemOpen, 2018, 7, 934-952.

2 (a) S. Dalapati, S. Jana and N. Guchhait, Spectrochim. Acta, Part A, 2014, 129, 499-508 and references therein; (b) A. Bhattacharyya, S. C. Makhal, S. Ghosh and N. Guchhait, Spectrochim. Acta, Part A, 2018, 198, 107-114; (c) S. K. Padhana, M. B. Podha, P. K. Sahub and S. N. Sahu, Sens. Actuators, B, 2018, 255, 1376-1390; (d) P. Alreja and N. Kaur, Inorg. Chim. Acta, 2018, 480, 127-131; (e) L. Zang and S. Jiang, Spectrochim. Acta, Part A, 2015, 150, 814-820; (f) L. Zang, D. Wei, S. Wang and S. Jiang, Tetrahedron, 2012, 68, 636-641.

3 (a) R. Sivakumar, V. Reena, N. Ananthi, M. Babu, S. Anandan and S. Velmathi, Spectrochim. Acta, Part A, 2010, 75, 11461151; (b) Q. Li, Y. Guoa, J. Xua and S. Shao, Sens. Actuators, B, 2011, 158, 427-431; (c) K. Liu, X. Zhao, Q. Liu, J. Huo, H. Fu and Y. Wan, J. Photochem. Photobiol., B, 2014, 138, 75-79; (d) S. Dalapati, M. A. Alam, S. Jana and N. Guchhait, J. Fluorine Chem., 2011, 132, 536-540; (e) X. Huang, Y. He, Z. Chen and C. Hu, Chin. J. Chem., 2009, 27, 1526-1530; (f) X. Bao, J. Yu and Y. Zhou, Sens. Actuators, B, 2009, 140, 467472.

4 (a) P. A. Gale, N. Busschaert, C. J. E. Haynes, L. E. Karagiannidis and I. L. Kirby, Chem. Soc. Rev., 2014, 43, 205-241; (b) M. Wenzel, J. R. Hiscock and P. A. Gale, Chem. Soc. Rev., 2012, 41, 480-520; (c) R. Custelcean, Chem. Commun., 2013, 49, 2173-2182; (d) S. K. Dey, A. Basu, R. Chutia and G. Das, RSC Adv., 2016, 6, 26568-26589; (e) C. Jia, W. Zuo, D. Zhang, X.-J. Yang and B. Wu, Chem. Commun., 2016, 52, 9614-9627; (f) D. Yang, J. Zhao, X.-J. Yang and B. Wu, Org. Chem. Front., 2018, 5, 662-690; (g) R. Custelcean, Chem. Soc. Rev., 2010, 39, 3675-3685.

5 (a) I. Ravikumar, P. S. Lakshminarayanan and P. Ghosh, Inorg. Chim. Acta, 2010, 363, 2886-2895; (b) S. K. Dey and G. Das, Chem. Commun., 2011, 47, 4983-4985.

6 (a) M. Boiocchi, L. Del Boca, D. E. Gomez, L. Fabbrizzi, M. Licchelli and E. Monzani, J. Am. Chem. Soc., 2004, 126, 16507-16514; (b) S. K. Dey, R. Chutia and G. Das, Inorg. Chem., 2012, 51, 1727-1738; (c) A. Pramanik, M. E. Khansari, D. R. Powell, F. R. Fronczek and M. A. Hossain, Org. Lett., 2014, 16, 366; (d) I. Ravikumar and P. Ghosh, Chem. Commun., 2010, 46, 1082-1084; (e) U. Manna and G. Das, CrystEngComm, 2018, 20, 3741-3754; (f) U. Manna, S. Kayal, S. Samanta and G. Das, Dalton Trans., 2017, 46, 10374-10386.

7 D.-G. Cho and J. L. Sessler, Chem. Soc. Rev., 2009, 38, 16471662. 